Veterin. Inst. d. Fachabteilung d. Fischerei u. Tierzucht, Univ. Hiroshima (Vorstand: Prof. Y. TSUJI) u. Anat. Inst. d. Med. Fak., Univ. Okayama

(Vorstand: Prof. M. SEKI).

\title{
Beobachtung der Mitochondrien in den normalen und gereizten Bindegewebszellen des Unterhautgewebes der Maus nach einer Versilberungsmethode. 二十日鼠の皮下組織の正常と刺戟された結織細胞内の 糸粒体の銀染法による観察。
}

\author{
Shunsaku FUJII 藤 井 俊 策.
}

(Eingegangen am 7. Dezember 1956.)

Über die Mitochondrien in den Bindegewelszellen liegen schon viele Studien an lebenden und fixierten Zellen vor, z. B. von WEATHERFORD (1933), YAMASHITA (1948) und MORI (1955). Vor kurzem hat der Verfasser (1956) eine Methode gefunden, die durch Versilberung eine sehr distinkte Darstellung der Mitcchondrien ermöglicht, und nach dieser Methode die Mitochondrien in verschiedenen Zellen des Epithelsystems gefärbt und beobachtet. In der vorliegenden Arbeit wurden die subkutanen Bindegewebszellen nach dieser Methode untersucht.

\section{Material und Methode.}

Erwachsene Mäuse wurden durch ein starkes Auseinanderziehen ihrer Wirbelsäule getötet, und die REGAUDsche Fixierungsflüssigkeit wurde in die Unterhaut des Rückens in einer großen Menge injiziert. Nach 2 Stunden nahm man kleine Stückchen des subkutanen Bindegewebes heraus, verbreitete sie auf dem Objektglas und verfertigte Häutchenpräparate, welche für weitere 3 Stunden in der REGAUDschen Flüssigkeit eingelegt wurden. Eine solche Fixierungsweise brachte im Vergleich zu den in frischem Zustand in die Fixierungsflüssigkeit gebrachten Häutchen ein besseres Resultat.

Das Unterhautgewebe wurde in einem anderen Versuche zuvor indirekt gereizt, indem man die Haare des Rückens rasierte und die Haut mit Crotonöl bepinselte. Dabei wurden nach Ablauf von 2, 4, 6, 8, 12 und 24 stunden Gewebestückchen aus der Unterhaut ausgenommen und wie oben behandelt. Es wurde aber auch eine kleine Menge von $0.2 \%$ iger Colibazillensuspension direkt in die Unterhaut eingespritzt, um das dortige gereizte Gewebe wie oben $\mathrm{zu}$ untersuchen. 
Nach Ahspülen in Wasser wurden die Häutchenpräparate versilbert, aber diesmal verwandte man besser eine dünnere $0.25-0.5 \%$ ige GelatineSilbernitratlösung und 0.04\%ige Gelatine-Hydrochinonlösung. Zum Vergleichen wurden die Bindegewebshäutchen auch nach HEIDENHAIN mit Eisenhämatoxylin gefärbt.

\section{Ergebnisse und Auswertung.}

Nach der Versilberung erscheinen in den Bindegewebszellen der Unterhaut zahlreiche Gebilde von Granula-, Stäbchen- und Fadenform in Schwarz. Solche geschwärzten Gebilde sind aus ihrer Form, Zahl und Verteilung im Zelleib ohne Zweifel zum größten Teil in die Mitochondrien einzureihen. Im folgenden sollen acht Photographien gezeigt und darüber eine Erläuterung gegeben werden.

\section{A. Die Mitochondrien in den normalen Bindegewebszellen in der Unterhaut.}

Im subkutanen Bindegewebe finden sich bekanntlich Fibrocyten, Fibrohistiocyten, Histiocyten, Monocyten und zuweilen leukocytäre Zellen, wobei die Fibrocyten am meisten zu sehen sind. Die Mitochondrien in den Fibrocyten sind, wie in Abb. 1 dargestellt ist, zum größten Teil fadenoder stäbchenförmig und zum Teil hanterförmig oder körnig. Durch eine genauere Beobachtung wird bestätigt, daß fadenlörmige Mitochondrien sich gewöhnlich mehr in den Ausläufern den Zellen, granuläre Formen sich aber mehr in der Umgebung des Kerns finden. Die Mitochondrien finden sich zuweilen im Zelleib gleichmäßig verteilt vorhanden, zuweilen aber mehr in einem bestimmten Teil des Zelleibes oder in einem Ausläufer des letzteren vorhanden.

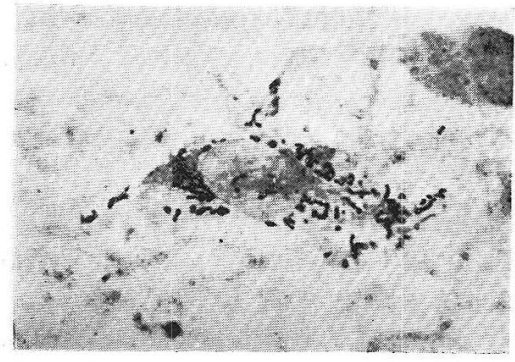

Abb. 1. Fibrocyten aus dem normalen Unterhautgewebe, versilbert. Die schwarz imprägnierten Gebilde sind sicherlich Mitochondrien. Sie erscheinen aber viel dicker als bei Färbung mit Farbstoffen. $1000 \times$.

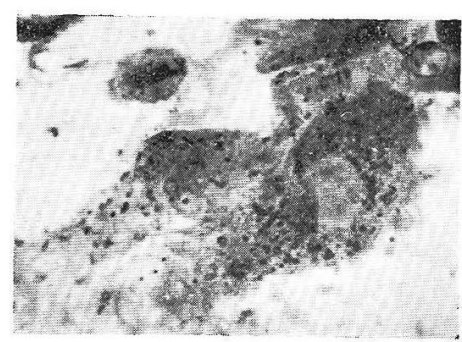

Abb. 2. Fibrohistiocyten und Histiocyten aus dem normalen Unterhautgewebe, versilbert. Die dick dargestellten Mitochondrien sind meist körnig und verteilen sich im ganzen Cytoplasma. $1000 \times$. 
In den Fibrohistiocyten sind die Mitochondrien meistens granulär, aber es kommen auch solche von Stäbchenform, wenn auch in kleiner Zahl, vor. Die auf der linken Seite vorhandene Zelle in Abb. 2 ist ein Übergang von einem Fibrocyten zu Fibrohistiocyten. Die auf der rechten Seite vorhandene ist ein ausgebildeter Histiocyt. Die Mehrzahl der körnigen Gebilde isind wahrscheinlich Mitochondrien, aber bei den anderen handelt es sich vielleicht um Granula von verschiedener Natur. Sie sind im Cytoplasma gleichmäßig verteilt. Diese Befunde und Annahmen ließen sich durch die Vergleichung mit den Angaben anderer Forscher, die zur Untersuchung andere Fixierungsmittel verwandten und andere Färbungen vornahmen, bestätigen. Verglichen wurden z. B. die Angaben von YAMASHITA (1948), der Häutchenpräparate des Unterhautgewebes der Maus nach der Fixierung in der LEVIschen Flüssigkeit mit Eisenhämatoxylin nach HEIDENHAIN färbte, und die von WEATHERHORD (1933), der Häutchen- und Schnittpräparate des Unterhautgewebes des Kaninchens nach der Fixierung in der ZENKERschen Flüssigkeit nach der ALTMANNschen Anilin-Fuchsinmethode und mit Eisenhämatoxylin färbte.

\section{B. Die Mitochondrien in den gereizten Bindegewebszellen in der Unterhaut.}

Auf Grund der Reizung wandeln sich die noch nicht hoch differenzierten Bindegewebszellen im Unterhautgewebe in verschiedene Zellformen um. In unserem Institut konstatierte MUKOHATA (1941), daß durch die Bepinselung von Crotonöl auf die Haut der Maus die Fibrocyten im subkutanen Gewebe sich in Fibrohistiocyten und Histiocyten umwandeln. Ich untersuchte die Mitochondrien in den sich so ändernden Bindegewebszellen nach der Versilberung.

Schon in der Zeit 2 Stunden nach der Bepinselung mit Crotonöl vermehren sich abgerundete Fibrohistiocyten mit Vakuolen. Die Mitochondrien in derartigen Zellen sind im allgemeinen kürzer, dicker und etwas zahlreicher als in den Fibrocyten. Sie finden sich verhältnismäßig zahlreich um den Kern herum.

Solche Veränderungen werden 4 Stunden nach der Bepinselung noch ausgesprochener (Abb. 3). Auch treten Vakuolen in vermehrter Zahl im Cytoplasma der Fibrohistiocyten auf. Man sieht manchmal solche Zellen, die in ihrem Cytoplasma ring- und halbringförmige Mitochondrien haben (Abb. 4). Sie ähneln den ringförmigen Mitochondrien, die LEWIS (1915), RICHARDSON (1934) u. a. in degenerierten Fibrocyten in vitro beobachtet haben. Ein Teil von ihnen sind möglicherweise GOLGIsche Körperchen, fettige Tröpfchen oder aber Vakuolen im allerersien Stadium der Bildung.

6 Stunden nach der Bepinselung treten im Cytoplasma der Fibro- 


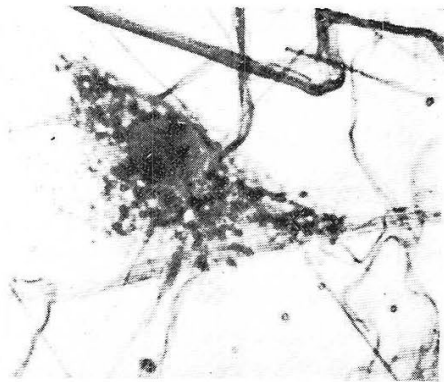

Abb. 3. Fibrohistiocyt aus dem Unterhautgewebe, 4 Stunden nach der Bepinselung von Crotonöl, versilbert. Die Mitochondrien sind kurz und dick. Man sieht zahlreiche Vakuolen. $1000 \times$.

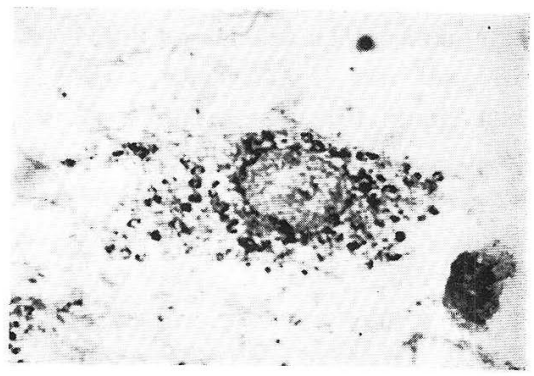

Abb. 4. Fibrohistiocyt aus dem Unterhautgewebe, 4 Stunden nach der Bepinselung von Crotonöl, versilbert. Man sieht ring- und halbringförmige Einschlüße. $1000 \times$.

histiocyten zahlreiche Vakuolen auf, zwischen denen man Mitochondrien von verschieden Formen sieht. Die sehr langen Gebilde in Abb. 5 und 6

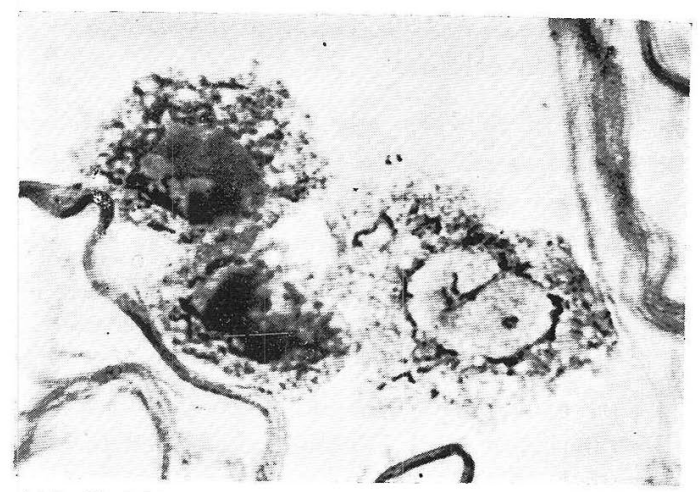

Abb. 5. Fibrohistiocyten aus dem Unterhautgewebe, 6 Stunden nach der Bepinselung von Crotonöl, versilbert. Die Mitochondrien sind vielerorts in langer Form dargestellt, daneben zahlreiche große Vakuolen sind zu sehen. Ein Teil der schwarzen Gebilde ist möglicherweise fettige Einschlüße. $1000 \times$.

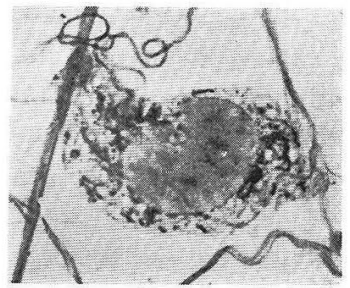

Abb. 6. Beschreibung wie bei Abb. 5.

sind vielleicht eine Folge der ungünstigen Versilberung. Im Bezirke des Zelleibes mit zahlreichen Vakuolen kommen im allgemeinen Mitochondrien nicht oder kaum vor.

8 Stunden nach der Bepinselung vermehren sich Fibrohistiocyten in verschiedenen Entwicklungsstufen beträchtlich, wie in Abb. 7 dargestellt, ist. Die links oben in der Abbildung vorhandenen zwei Zellen sind als abgerundete Histiocyten anzusehen. In den Zellen sind neben den als 
Mitochondrien anzusehenden Gebilden auch solche von anderer Natur und von mannigfachen Gestalten vorhanden.

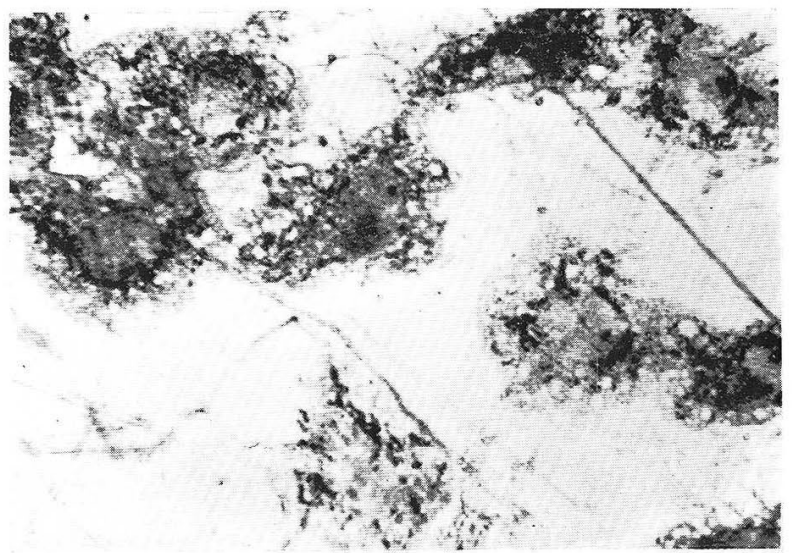

Abb. 7. Histiocyten und Fibrohistiocyten aus dem Unterhautgewebe, 8 Stunden nach der Bepinselung von Crotonöl, versilbert. Die Form, Verteilung und Zahl der schwarzen Gebilde sind sehr verschieden. $1000 \times$.

Nach 12 Stunden der Bepinselung vermehren sich Histiocyton in weiterem Maßa an $\mathrm{Zahl}$, deren Cytoplasma aber Mitochondrien in geringer Zahl einschließt. In diesem Stadium vermindern sich die Fibrocyten stark.

Kurz zusammenfassend läßt sich sagen, daß durch Bepinselung von Crotonöl auf die Haut die Fibrocyten anfangs sich ihre Fortsätze abkürzen und sich abrunden, wobei die im ganzen Bercich des Zelleibes vorhandenen Mitochondrien sich an Zahl etwas vermehren und eine Neigung zur Ansammlung in der Umgebung des Kerns zeigen, daß alsdann mit dem Auftreten von Vakuolen im Cytoplasma die Mitochondrien sich wieder im ganzen Bereich des Cytoplasmas verteilen, bis sie sich schließlich mit der weiteren Vermohrung und Vergrößerung von Vakuolen vermindern. Es scheint also, daß die Vaktolen zum Teil aus den Mitochondrien entstehen.

Früher hat auch WEATHERFORD (1933) nach der Einverleibung des Schafserums in die Unterhaut des Kaninchens die Umwandlung der Fibrocyten in histiocytäre Formen bestätigt und konstatiert, daß die Mitochondrien kürzer und körnig werden.

Auch untersuchte YAMASHITA (1944) am Kaninchen die durch das Baden in Quellwässern hervorgerufenen Veränderungen der Mitochondrien in den fibrohistiocytären Zellen und kam zu den gleichen Resultaten. Der Abb. 8 liegt schließlich das Unterhautgewebe in der Zeit 12 Stunden nach einer Injektion von Colibazillensuspension zugrunde. Die meisten Zellen sind die von fibrohistiocytären Formen. Sie sind mit zahlreichen Mitochondrien, fettigen Tröpfchen und kleinen Vakuolen versehen. 


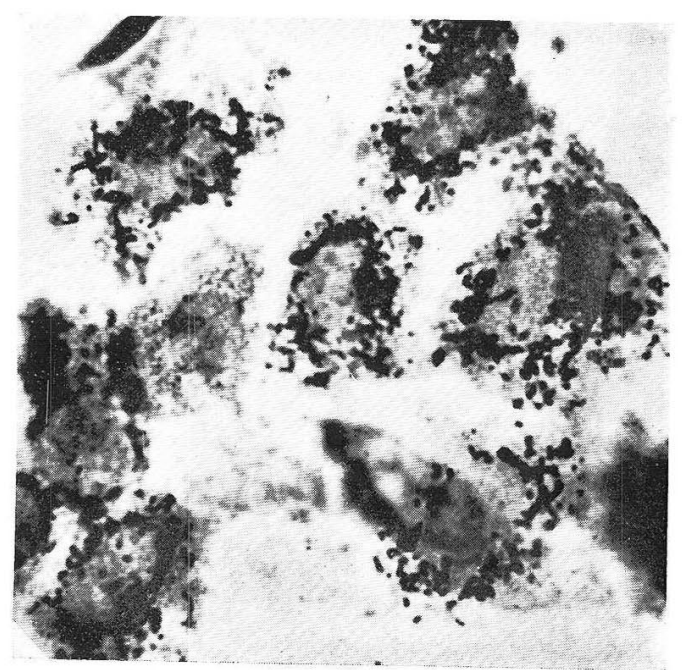

Abb. 8. Fibrohistiocyten aus dem Unterhautgewebe, 12 Stunden nach der Injektion einer Suspension von Colibazillen, versilbert. Man sieht dicker dargestellte Mitochondrien, fettige Einschlüße und Vakuolen. $1000 \times$.

\section{Zusammenfassung.}

Es wurden die Mitochondrien in don normalen und gereizten Bindegewebszellen der Maus nach der: Versilberungsmethode vom Verfasser (1956) imprägniert und beobachtet. Die Mitochondrien in den Fibrocyten sind zum größeren Teil fädig oder stäbchenförmig, die übrigen aber körnig. Sie verteilen sich in dem ganzen Bereich des Zellcibes. Dic Mitochondrien in den Fibrohistiocyten sind etwas größer und zumeist körnig oder stäbchenförmig und in der Umgebung des Kerns verhältnismäßig viel vorhanden. Sie werden beim Umwandlung der Fibrohistiocyten in Histiocyten alle in granuläre Form, und nehmen an Zahl ab. Zu gleicher Zeit entwickeln sich im Zelleib zahlreiche Vakuolen. In degenerierten Zellen scheinen fettige Einschlüße auch imprägniert zu werden, so daß ein sicheres Unterscheiden der Mitochondrien von ihnen kaum noch möglich ist.

\section{內 容 自 抄。}

著者の銀染法で標題つ研究が行われた，線維細胞の糸粒体は少しく粒状 のものああるが，多くは糸状または杆状で，公く胞形質内分散している. 線組球つものはやや大きい䊀状か太い杆状で, 核の周り飞比較的多い。線 組球が組織球となるとさに糸粒体はみな䊀状になり，数が減じ，同時に空 
胞が数多く発達する，但し変性した細胞では脂肪様包含体す銀染されるよ うであり，糸粒体とそれとの間に確かな区別がつかなくなる。

\section{Literatur.}

Fujii, Sh.: Methode zur sehr elektiven und sehr distinkten Darstellung der Mitochondrien durch Versilberung. Arch. hist. jap. 11 (1956). - Lewis, M. R. a. W. H. Lewis : Mitochondria (and other cytoplasmic structures) in tissue cultures. Amer. J. Anat. 17 (1915). - Mori, Ch.: Einteilung der mit Neutralrot und Janusgrün supravital gefärbten Bindegewebszellen aus dem lockeren Gewebe der Unterhaut der Maus. Arch. hist. jap. 7 (1955). - Mukohata, T.: Ex perimentelle Untersuchungen über die Umwandlungsfähigkeit der Zellen im Subkutangewebe der Maus. III. Versuche mit Crotonöl. Okajimas Fol. 20 (1941). - Richardson, K. C. : The Golgi-apparatus and other cytoplasmic structures in normal and degenerate cells in vitro. Arch. exper. Zellforsch. 16 (1934). - Weatherford, H, L. : Chondriosomal changes in connective-tissue cells in the initial stages of acute inflammation. Z. Zellforsch. 17 (1933). - Yamashita, S. : Plastosomen und Golgischer Apparat in den subkutanen Bindegewebszellen der Maus. I. Befunde am normalen Gewebe. (Jap.) Kaibo Z. 23 (1948). - II. Veränderungen durch das Bad im Quellwasser von Beppu. (Jap.) J. Jap. Balneo-climatol. Ass. 10 (1944). 